\title{
Historical Antecedents of Cancer from 1805 to 1891
}

\author{
Wilson I B Onuigbo*
}

(Received 19 July 2014)

\begin{abstract}
Abstarct
Cancer in terms of its origin was still a mystery. It has multiple etiologic factors, including ineffectiveness of immunologic surveillance. The distribution of human cancers points to a progressive accumulation of somatic genetic error. Sir Macfarlane Burnet has made immense contributions in the field of cancer surveillance. This paper analyses how the old masters were watching out for the hidden antecedents of cancer.
\end{abstract}

Key words: Cancer, Epithelium, Etiological factor, Microscopic, Somatic, Tumours.

\section{INTRODUCTION}

The influence of Sir Macfarlane Burnet in the field of immunologic surveillance of cancer was immeasurable. This was partly shown in his Brailsford Robertson Memorial Lecture on "Morphogenesis and cancer" published in 1977. Of current interest is that, in his introductory remarks, that great man recommended scientists to acquaint themselves with historical antecedents. Let us therefore, review the writings of the old masters from 1805 to 1891 in order to elucidate the development of this phenomenon which ultimately culminated between 1888 and 1891 in significant statements encompassing even the very word "immunity."

\section{Historical Perspectives}

The requested reprint, as one sees it (Onuigbo, 1985, pp. 7-9; Onuigbo, 1985, pp. 37$39)$ is a tracer tool in diverse disciplines. In this context, the author became a private possessor of the 1977 reprint autographed and sent to him by the renowned Sir Macfarlane Burnet (Burnet, 1977, pp. 5-9). He himself had written in his paper that, since 1957, he had been of the opinion that "the distribution of human cancers points to a progressive accumulation of somatic genetic error." In particular, as he concluded, almost all cancer has multiple etiologic factors, including "ineffectiveness of immunologic surveillance."

Surveillance implies keeping a close watch. Therefore, this paper analyses how the old masters were watching out for the hidden antecedents of cancer. In sum, they tried laboriously to get to the bottom of the mysteries of human cancer.

Cancer in terms of its origin was definitely one of the mysteries. It was, for example, viewed searchingly as far back as 1805 by Young (Young, 1805, pp. 51-53) as follows:

Whenever there is an inability in the system to restore an injured part to its original form by the ordinary action, we constantly find some new action assumed: -Nature would seem, as it were, to try her next best. Thus, in many cases of fractures, where there is great debility or old age, cartilaginous or tendinous mediums supply the place of bony union. An injured or weakened coat of an artery is often attempted to be strengthened by

*Founder-Director, Medical Foundation \& Clinic, 8 Nsukka Lane, Enugu 400001, Nigeria. Email: wilson.onuigbo@gmail.com 


\begin{abstract}
a bony lamina or patch; and, in scirrhous formations or changes, a marked and very extraordinary attempt is frequently evinced to correct the deranged state of things, by reducing the whole into one insensible and homogenous mass: and here, at the same time, is afforded the most direct evidence of the disease of cancer arising and depending on simple altered organization only. The very source and supply of the disease is an assimilation of various and unequal structures, giving rise to dissimilar actions. What then could Nature do better (when all her attempts have failed to restore an equilibrium of parts) than what she very often effects, viz. reducing the whole into a bony mass? Here all discordancy of action is at once destroyed, and an attempt at natural cure in scirrhus is clearly evinced, which shuts out the idea of a "specific virus." This attempt at natural cure is frequently exemplified in the examinations of true scirrhi, a progressive change into bone being often evident; in many the centres are completely ossified. Such attempts have been still more successfully accomplished in the ovaria, these parts having been found wholly converted into bone by the cancerous action.
\end{abstract}

Action in this field was examined by an anonymous Editor (1888, pp. 29-30) in 1888. He mentioned that "The question of the nature and cause of malignant new growths is attracting a large share of attention from pathologists of the present day." Next, he asserted that "The question 'What is cancer?' embraces the more important question, "What is the cause of cancerous infectivity?"' Meanwhile, one explanation had to his knowledge been offered thus:

Indeed, once the epithelium has transgressed the bounds of the basement membrane, it must almost of necessity infiltrate the tissue in which it comes to lodge. According to its primary seat, whether this be a gland, or a mucous surface, or the skin, so will it reproduce its original characters when it becomes so displaced. But being no longer, as it were, held in check, by having to subserve a definite function, its new development is irregular and wild, and the symmetrical cell arrangement of the physiological formation is often barely to be recognized in the disorderly massing of cells that constitutes the pathological product.

Product showing any pathological dimension was then being differentiated in terms of activities of one type or the other. Thus, Theodor Billroth (Billroth, 1871, p. 555) was of the firm view that "in the anatomical composition of different parts, certain continuous disturbances may exist which interfere with the occurrence of regulating processes, and which, from an irritation that at another spot would have induced a simple inflammation, excite an irritation from which the specific tumor is developed."

Developed along their distinctive ways were the ordinary and the cancerous tissues. Note how James Paget (Paget, 1835, pp. 567-568) saw their respective development in 1853 :

\footnotetext{
In like manner, the elemental cancerstructures show no method of growth or development which is without parallel in natural structures; they are formed and increased according to the same general laws as are observed in the normal rudimental structures; their peculiarities, in this regard, are chiefly in the seeming disorder that often prevails among them,-in the absence of an apparent singleness of design.
}

Design was appreciated by William Walshe (Walshe, 1846, pp. 5-7, 25) in $1846 . \mathrm{He}$ did so in the light of definable diversity. Consider how he comprehended the problem:

This diversity of characters is, indeed, the great difficulty with which the pathology of tumours has to contend; but the diversity is not to be called inconstancy: it is due to the fact that each tumour has, like each natural tissue, its phases of development, of degeneration, and of disease. Now we have scarcely yet begun the study of the variations to which, in 
each of these phases, the several tumours are liable. We may have learned, for example, the general characters of cartilaginous tumours, as they grow in the most favourable conditions; but how little do we know of the various aspects these may present when they fail of due development, or fall into various diseases, or variously degenerate! Yet all these changes have to be studied in the history of every tumour; and it would be as reasonable to charge any natural tissue with inconstancy, because it is altered in development and disease, as to hold that the similar diversity of tumours is an objection to their classification according to their structure. However, while I put this aside as an objection against classification, let me not be thought to underrate it as a difficulty; it is the great difficulty with which we have to contend. The work we have to do is not only to distinguish each kind of tumour from all other kinds, but, and in order to this end, to distinguish, as I may say, each kind from itself, by learning in each all the changes occurring in the various stages of its life.

Life and death factors were considered during the extensive "Discussion on Cancer" which was held at the Pathological Society of London in 1874. In the words of the opening discussant, Campbell de Morgan (de Morgan, 1874, p. 300), "Cancer has been there potentially for years, but its time has not come." Then, as he expatiated,

While I believe it probable that the germs of cancer may thus remain in a sort of dormant condition for long periods of time, I would by no means imply that there is not in cancerous patients a special disposition to tissue change, located in some but not in all the structures of the body. The general tendency to degeneration may give rise to the primary local change; so may local irritation. Thus out of a hundred chimney sweeps or claypipe smokers a certain number may have chimney sweep's cancer or lip cancer, the number varying, perhaps, according to the duration and extent of the irritation. But the majority will not become cancerous, irritate how you will; and of the remainder few probably would have cancer unless irritations were applied.

Applied as a force majeure in cancer illness was a superior element. It was conjured up in terms of "molecules" by John Simon (Simon, 1878, pp. 219-224) during the 1878 Annual Inaugural Meeting of the Midland Medical Society at Birmingham. "Among such supposed molecular irregularities," he reasoned, "the simplest we can imagine would be that, in the distribution of matters and force among so many millions of molecules, sometimes there results here and there a supernumerary or superpotential molecule." Next, he averred that:

Our present aetiological position seems, in short, to be this. In the genesis of the primary cancer, we have evidence of two forces: one, the natural growth-power of the texture, the other a power which is at least relatively foreign; and the cancer, which will act zymotically on other organs, expresses the co-operation of those two powers. Whether the process, as regards its unknown factor, depends, directly or indirectly, on some contagium from the outer world, or is from first to last merely the abnormal play of forces native to the body, is the question which waits to be solved. In our present imperfect state of knowledge with regard to many of the requisite elements for judgment, it would, I think, be unwise to attribute impossibility to either of the alternatives. In relation to them both, as well as to other conceivable hypotheses of cancer, our scientific need and duty is to continue observing, as accurately as we can, every local and personal and hereditary condition which may seem to act, either attractively or repellingly, on the factor which it is our aim to understand; and of such indications there are already some which I think valuable. Thus, for instance, the fact (above noted) that cancer has marked affinity for organs 
which are already in certain accidental ways disordered, seems to show that the unknown exciting cause either is not native to the body, or at least is not specially an attribute of the texture in which the disease breaks out. And the fact (as it appears to be) that cancer, though eminently contagious from part to part in the affected body, can hardly, if at all, be communicated to any other body, even among animals of the same sort, by artificial inoculations, injections and transplantations, seems to say-first, that the unknown factor in cancer can only operate where certain general predisposing conditions exist,- and, secondly, that cancer is perhaps not an hereditary disease, except as regards those predisposing conditions.

Conditions par excellence were best appreciated at the microscopic level. Thus, when William Budd (Bud, 1842, pp. 266-270) read his own paper before the Bristol Medical Society in 1842, he was definitely persuasive:

Under the microscope, vegetable parenchyma and cartilage, in its early state, are one. For essential distinctions of nature we must turn to other qualities and other attributes. Need I say how widely those of cancerous growths separate them from the natural tissues of the body? I have laid some stress on this point, because I think it one of much importance; for there can be no doubt that this essential difference of nature between cancerous growths and the normal tissues of the body is closely connected with the independent powers of life and nourishment these growths posses, if not their very foundation.

Foundation was all the time being sought seriously. According to the slant that Rivington (Rivington, 1874, pp. 373-374) maintained during the aforesaid "Discussion on Cancer" in 1874, it consists "in the multiformity of elements, the disorderly crowding of elements, the abnormal growth of natural elements." As a follow up, he added that "the question then arises, how does this disorderly crowding and this abnormal growth of natural elements occur?" Moreover, he answered thus:

But cells cannot of themselves throw off natural laws. So long as they are placed in normal conditions they will obey the normal laws of growth and development, and it is only when they are placed in abnormal conditions that they will develop abnormally. But the whole question under discussion is, what are the abnormal conditions which cause the cells to grow and develop abnormally? Cancer was called by Mr. Hutchinson a rebellion of cells, and no doubt it may be so; but what is it that causes the cells to rebel?

Rebel status of cancer cells was discussed by William Walshe (1846, p.25) extensively:
It is not in the likeness or in the unlikeness to the natural tissues that we can express the true nature of tumours: it is not enough to consider their anatomy; their physiology, also, must be studied: as dead masses, or as growths achieved, they may be called like or unlike the rest of a part; but, as things growing, they are all unlike it. It is, therefore, not enough to think of them as hypertrophies or overgrowths: they must be considered as parts overgrowing, and as overgrowing with appearance of inherent power, irrespective of the growing or maintenance of the rest of the body, discordant from its normal type, and with no seeming purpose.

To all this, I know, it may be objected that tumours, and other like growths, may cease to grow, or grow unequally, and yet are tumours still. But this is only in appearance opposed to what I have said, which is no more than that the best or only time, in which we may discern the true difference of these from other growths, is the time of their active increase. As we can have no complete idea of any living thing, unless it include the recognition of its origin, and of its passage through certain phases of development and growth; so must our thoughts of these 
abnormalities be imperfect or untrue, unless we have regard to their development, and growth and maintenance, as independent parts. But, indeed, the cessation of growth in tumours and the allied diseases often affords evidences of their peculiar nature, confirmatory of that deduced from their increase. Such cessation may occur when they have attained a certain regular size; as in the painful subcutaneous tumours, the osseous tumours on the phalanges of great toes, and some others, which, perhaps always, cease to grow when they have reached a limit of dimensions that appears as natural and constant for them as the average stature is for the individuals of any species. Or, the cessation of growth may occur when the tumour calcifies, or when a mammary glandular tumour is absorbed. But it is to be observed that these events are, or may be, as irrespective of the nutrition of all the rest of the body, as the development and growth of the tumour were; and that, except in the comparatively rare event of the absorption of a tumour, there is, in no case, an indication of return to the normal type or condition of the body: there is no improvement, as in the organized lymph exuded in the inflammatory process, no adaptation to purpose, no assumption of a more natural shape. In all these events, therefore, as well as in their growth, the nearly independent nature of the tumour is shown: while forming part of the body, and borrowing from it the apparatus and the materials necessary to its life, the tumour grows or maintains itself, or degenerates, according to peculiar laws.

Laws of natural growth were contrasted with those of cancerous growth by Savory (Savory, 1884, p. 34) during the Bradshaw Lecture on the Pathology of Cancer delivered in 1884 at the Royal College of Surgeons. Concerning normal growth and development, he posited that "these continue up to a certain point, and then suddenly cease." In contrast, regarding malignancy, he felt that one may as well assume that "their development implies that the tissue-changes in which they live and grow have ceased to be normal." As he continued, "They are not bound by the conditions of their existence to be local; but they can invade parts and flourish still." He even went further to elaborate thus:

Tumours are living structures, distinct
outgrowths in some part or other, of the
body; local, or limited to a particular
place, in inverse ratio to the capability of
their elements to adjustment to different
conditions of life. Like the natural
structures and organs, they have an
independent life of their own, which is
more or less influenced, modified, and
controlled by the life of the body. Like
natural structures, they have an inherent
power of maintenance, but this power is
regulated by the condition of the body in
general.

General manifestation was not enough and therefore specificity was canvassed by Velpeau (Velpeau, 1856, p. 475) from France:

Consequent on some external influence, or on some molecular action, a slight infiltration, an exudation of blood, of albumen, of plastic, or of secretory material, takes place in the structure of some tissue or other; and whether this material escaped from the parts where it naturally exists, forms a mass of certain size, or becomes reduced into smaller masses, is a matter of little consequence, since it acts as a foreign body, and thus is enough to constitute the germ of a disease. Deriving substance from the part in which it exists, it by no means remains as inert material. Its vitality, if it has ever ceased, is renewed; new molecules are associated to the primary ones, and thus a tumour may commence its individual existence. This tumour increases in size, and becomes developed at the expense of the surrounding organism; a thousand changes may take place in its form or size, or even in its composition, and all this without its necessarily losing its character as a local disease. 
Disease of such a bewildering nature as cancer was certainly a challenge during a Meeting of the Glasgow Medical Society in 1897. On that occasion, Joseph Bell (Bell, 1857, pp. 415-432), a physician, presented "the more singular and interesting of the cases which (he had) seen in the clinical wards during the past year." As he perceived, "The very obscurity which invests the disease adds to its interest." Then he lamented that "Every step in our investigation as to its origin and nature, is involved in great difficulties." Furthermore, he felt that "Even granting the cancer cell to have an interior origin, our notions regarding its nature will not be much advanced. We are unable to trace it to any of the healthy cellular formations."

Formations of note were espoused by John Marshall (Marshall, 1889 p.1045-9) in the Morton Lecture on Cancer and Cancerous Diseases. When he delivered it at the Royal College of Surgeons in 1889, his own hypothesis was down to earth:

We must endeavour to search out this mystery, to look into the minute anatomy of the nucleus of the cancer cell. That is a hopeful, and it does not seem to me at all an impossible, thing. We shall find it, no doubt anarchic, but shall we not be able to trace the steps of the anarchy? Shall we not hope as it were, to unfold the mystery of mysteries which lies in the nucleus of a cancer cell?

But if we proceed further with regard to these cells, we find it is not only their structure which we must study, but we must study their composition. And here, again, it is by the agency of different tests acting upon them that we are able to discriminate between certain important portions of a healthy cell. Why should not this mode of an analysis be applied at once to an unhealthy cell? Are there not swarms of agents in nature-colouring matters, chemical substances, and other thingswhich should be forthwith tried, to see whether we can develop by this sort of polarization - not of light, but of chemical agency-abundant characters in these unhealthy cells which will lead us to see how they become anarchic and unhealthy?

Unhealthy state of knowledge itself was brought to the fore two years later at the time that he became President of the General Medical Council. Be it noted that he then brought in the word immunity as I will italicize as follows (Marshall, 1889, pp. 1045-1049):

\begin{abstract}
Whether we can go still further, and secure for healthy tissues immunity against infection from an existing cancer-a resistance to invasionremains a subject for future inquiry. All we can yet say is, that under certain conditions the nutrition of cancer cells may be so far arrested as to lead to their complete disintegration. This is often observed in small fragments, or within a limited circumference, and Nussbaum has recently succeeded in the attempt to effect such changes in larger growths by cutting off their supply of blood. He makes deep furrows with Paquelin's cautery through the integuments and subcutaneous fat quite down to the adjacent fascia or muscles, thus cuts off all peripheral supply of blood, and so lessens the abnormal vascularity of many malignant tumours. Soft fungoid masses which bleed readily soon become firm, and the whole tumour more solid, while the general health improves and life is prolonged. And we also hear from Munich of aims at a somewhat similar object by injecting solutions of ozone into the substance of cancerous growths and the tissues surrounding them. Not only is the proliferation of the epithelial cells said to be arrested, and the formation of cicatricial tissue obtained, but the surrounding textures are protected against invasion.
\end{abstract}

\section{Conclusion}

Near the end of the century, invasion and immunity were interlinked by Sir Spencer Wells (Wells, 1888, pp. 1203, 1266) during the Second Morton Lecture on Cancer and Cancerous Diseases. Convincingly, He delivered it at the 
Royal College of Surgeons of England. Future prospects, be it noted, were apparent going by his own words:

\begin{abstract}
Again, an apparently increased personal liability may be really a diminished power of resistance, and vice versa; and an apparently positive immunity may be quite accidental, and not due to any constitutional conditions. The alleged steady increase of cancer amongst our own population at all periods of life, especially at the period of greater liability, and more amongst males than females, involves serious considerations. The disease is now said to prevail more in England than in Ireland: but, on the other hand, it has been pointed out that in the United States it is more prevalent amongst those of Irish and of German descent than amongst the rest of the population. Still, further researches on all these points are required.
\end{abstract}

\section{BIBLIOGRAPHY}

Anonymous. The pathology of cancer. Lancet, ii (1888):2930.

Billroth, T. General surgical pathology and therapeutics, Hackley, C. E. (Tr.), New York, 1871, p. 555.

Bell, J. Remarkable cases of malignant (encephaloid) disease, occurring in Nos. 1 and 2 Medical Wards of the Glasgow Royal Infirmary, Glasgow medical journal, v(1857):415-432.

Budd, W. Remarks on the pathology and causes of cancer, Lancet, ii (1842):266-270.

Burnet, M. Morphogenesis and cancer, Medical journal of Australia, i(1977):5-9.

Chamber, A.F. MacDonald, I.C., Sahmidt, E.E., et al. Steps in tumor metastasis: new concepts from intravital videomicroscopy, Cancer metastasis review, xiv(1995):279-301.

de Morgan, C. Discussion on cancer. Transactions of the pathological society of London, xxv (1874): 300.

Kinnaert, P. Anatomical variations of the cervical portion of the thoracic duct in man, Journal of anatomy, $\operatorname{cxv}(1975): 45-52$.
Marshall, J. Morton lecture on cancer and cancerous diseases, Lancet, ii(1889):1045-1049.

Marshall, J. Observations on the nature of cancer, Lancet, ii(1891):415-417.

Morris, V.L. MacDonald, I.C., Koop, S., et al. Early interactions of cancer cells with the microvasculature in mouse liver and muscle during hematogenous metastasis: videomicroscopic analysis, Clinical and experimental metastasis, xi(1993): 377-390.

Onuigbo, W.I.B. Analyzing medicine by means of reprint requests, Methods of information in medicine, xxiv(1985):37-39.

Onuigbo, W.I.B. Reprint requests - a tool for documentation International forum on information and documentation, $\mathrm{x}(1985): 7-9$.

Onuigbo, W.I.B. The carriage of cancer cells by the thoracic duct, British journal of cancer, xxi(1967):496-500.

Paget, J. Lectures on surgical pathology, London, 1853, pp. 567-568.

Rivington. Discussion on cancer, Transactions of the pathological society of London, $\operatorname{xxv(1874):373-374.~}$

Savory, W.S. The Bradshaw lecture on the pathology of cancer, London, 1884, p. 34.

Simon, J. An address on some points of science and practice concerning cancer, British Medical Journal, i(1878):219-24.

Velpeau, A. A treatise on the diseases of the breast and mammary region. Henry, Mitchell (Tr.), London, 1856, p. 475.

Walshe, W.H. The nature and treatment of cancer, London, 1846, pp. 5-7, p. 25.

Wells, S. The Morton lecture on cancer and cancerous diseases, British medical journal, ii (1888): 1203 \& 1266.

Witte, M.H., Hanto, D., Witte, C.L. Clinical and experimental techniques to study the lymphatic system, Vascular surgery, xi(1977):120-129.

Young, S. An inquiry into the nature and action of cancer: with a view to the establishment of a regular mode of curing that disease by natural separation, London, 1805, pp. 51-53. 